\title{
FAILURE ANALYSIS OF PLUNGER ROD AND BARREL OF SUCKER ROD PUMPS
}

\section{D.A. STREKALOVSKAYA, A.D. DAVYDOV, D.V. LYASHENKO \& MAXAT TLESHEV}

National Technology Initiative Center for Advanced Manufacturing Technologies based on the Institute of Advanced Manufacturing Technologies of Peter the Great St. Petersburg Polytechnic University, Polytechnicheskaya, 29, St.Petersburg,, Russia

National Technology Initiative Center for Advanced Manufacturing Technologies based on the Institute of Advanced Manufacturing Technologies of Peter the Great St. Petersburg Polytechnic University, Polytechnicheskaya, 29, St.Petersburg,, Russia

National Technology Initiative Center for Advanced Manufacturing Technologies based on the Institute of Advanced Manufacturing Technologies of Peter the Great St. Petersburg Polytechnic University, Polytechnicheskaya, 29, St.Petersburg,, Russia

KMG ENGINEERING” LLP, Kabanbai street, 17, Nur-Sultan city, Kazakhstan

\begin{abstract}
This paper presents the results of a failure analysis of a plunger rod and a barrel of sucker rod pumps, which were used in an environment containing hydrogen sulfide. The chemical composition, mechanical properties and hardness of the details were studied to compliance assessment of the details material to technical documentation. The destruction of details surface was analyzed by optical electron microscopy. It was established that the plunger rod destruction occurred inside the adapter body on the first thread of threaded rod connection, and the barrel destruction was observed in the area of threaded connection with the pump suction valve body. Results showed that the main cause of the failure was combined action of corrosive H2S environment and mechanical effects that led to the sulphide stress corrosion cracking. Suggestions were put forward to extend the service life of sucker rod pumps parts and reduce the likelihood of their destruction.
\end{abstract}

KEYWORDS: Sucker-Rod Pumps, SPR, Failure Analysis, Plunger Rod, Barrel, Oil and Gas Industry

Received: Jun 09, 2020; Accepted: Jun 29, 2020; Published: Sep 25, 2020; Paper Id.: IJMPERDJUN20201414

\section{INTRODUCTION}

A significant number of oil field wells are equipped with sucker rod pumping units, whose share in oil production is increasing annually [1]. In addition to large advantages, these units have the disadvantages associated with downhole pumping equipment accidents. The reliability of sucker rod pumping equipment, its functionality and maintainability are determining factors for the effective operation of sucker rod pumps (SPR) [2].

During operation of wells by sucker rod pumping units the main failure problems are rods breakage and mechanical friction of SPR parts, in particular rod against tubing and plunger against barrel during long-term operation in wells [3]. Downhole pumping equipment depreciation depends on the presence of formation mineralized water in the well products. Formation water causes corrosion of pipes, rods and other parts and weakens their strength. Due to the above reasons, rods breakage leads to accidents, and leaks, which increase proportionally to the increase in clearance between a plunger and a barrel in SPR, completely reduce the pump capacity for several months of operation [4]. Also, accidents initiation may be due to non-compliance of the details material with the technical documentation (TD) 
requirements, the incorrect materials selection for operating conditions, the human factor, etc. [5].

Damage control at oil extraction spots is one of the most pressing and important problems and requires significant costs associated with downtime, repair and rectification of the consequences of accidents. Cost reduction is possible by preventing accidents by timely repair or replacement of damaged parts [6]. That is why works oriented to improving the operation efficiency of sucker rod pumps (SPR) are relevant.

Analysis of destroyed SPR parts and identification of destruction causes are necessary to recommend protective measures oriented to accidents prevention at operational locations.

The purpose of this study was identification of failure causes of the plunger rod and the barrel from two different sucker rod pumps after destruction during operation. For this, mechanical tensile tests, chemical composition analysis of details material, and hardness measurements were carried out. Fractures and destructions of the SPR parts were analyzed by optical electron microscopy.

\section{EXPERIMENTAL METHODS}

As an object of study, we used Russian-made details from two different deep-well sucker rod pumps after failure during operation: a plunger rod with a pump adapter and a barrel with a pump valve. According to the technical documentation (TD) sucker rod pumps details were operated in an environment containing $\mathrm{H} 2 \mathrm{~S}$ and $\mathrm{CO} 2$.

Hardness measurements and analysis of chemical composition and mechanical properties were carried out to conformity assessment of destroyed details material to TD.

The emission spectrometer «Iskroline-100» was used for chemical composition analysis of SPR parts by atomic emission spectroscopy in accordance with GOST 54153-2010.

Mechanical properties tests and sample preparation were carried out in accordance with GOST 1497-84, GOST 10006-80 and GOST 11701-84. Universal testing machine «INSTRON 8801» (100 kN) with software «Instron Bluehill 2.6» was used for mechanical tensile tests.

The macrohardness of investigated details was measured by the Rockwell hardness method using a hardness tester «TP 5006, No. 85» according to GOST 9013-59.

Additional microhardness studies were carried out using microscope attachment «MICRO-DUROMAT 4000E» in accordance with GOST 9450-76. Microhardness was estimated using the method of a restored imprint on an optical microscope «Reichert-Jung» at increase $\times 500$. Also, microhardness measurements were carried out by the Vickers hardness method with a load of $180 \mathrm{~g}(\mathrm{HV} 0,18)$. Hardness number conversion from HV scale to HRA scale was performed according to ASTM E 140 standard [7].

For metallographic studies, samples were cut from damaged details and pressed. After that sample's surfaces were prepared by grinding with 120 to 1200 grinding papers, followed by polishing with special cloth and diamond paste ( 3 and 1 micron). Grinding and polishing was carried out on a grinding-and-polishing machine «BUEHLER ECOMET 4». For metal microstructure developing etching of samples was performed with a $3 \%$ nitric acid $\left(\mathrm{HNO}_{3}\right)$ in alcohol. The metals structure was studied by optical metallography using a microscope «Reichert-Jung» at increase $\times 500$.

Chemical composition studies of inclusions were carried out using a raster electron microscope «SUPRA 55VP 
WDS» with an X-ray spectral analysis adapter.

\section{RESULTS}

\subsection{Compliance Study of Details to Technical Documentation}

\subsubsection{Plunger Rod of SPR}

Figure 1 shows the plunger rod of SPR with the pump adapter. As can be seen, the destruction occurred on the first thread of threaded rod connection inside the adapter body.

Plunger rod studies were carried out for compliance with the technical documentation requirements. Table 1 show the TD requirements for the plunger rod material and the mechanical testing results of the sample material.

According to the studies results of the plunger rod metal mechanical properties, the yield point was $680 \mathrm{MPa}$, and the tensile strength was $790 \mathrm{MPa}$.

The sample hardness is $340 \mathrm{HV}$ (34 HRC according to ASTM E140 [7]). In accordance with the NACE MR0175 Part 2 requirements for low alloy steels used in hydrogen sulfide-containing environment, the material hardness should be less than $22 \mathrm{HRC}$, in rare cases up to 26-33 HRC [8].

Table 2 shows studies results of plunger rod material chemical composition. According to the TD, the plunger rod material must comply with strength steel grade "D" in compliance with API Spec 11B [9], which includes 40CrMnMoA, $30 \mathrm{CrMoA}$ and $38 \mathrm{CrMnTi}$ steel grades.

According to the obtained chemical composition, it was found that the SPR plunger rod material corresponds to 40CrMnMoA steel grade, which complies with the TD requirements.

The plunger rod material is compliant with the technical documentation requirements regarding mechanical properties and chemical composition.
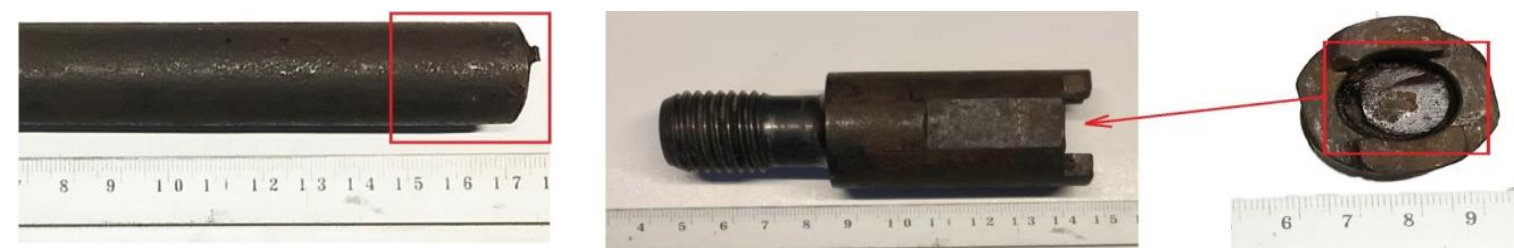

Figure 1: Plunger Rod of SPR With Its Adapter: a) Plunger Rod (Breaking Point is Marked Red); b) Adapter of Plunger Rod (Side View, Breaking Point is Marked Red); c) Adapter of Plunger Rod (Top View, Breaking Point is Marked Red).

Table 1: Results of Mechanical Testing of Plunger Rod, Compared With ED Values

\begin{tabular}{|c|c|c|c|}
\hline & Yield Point $\mathbf{\Sigma 0 . 2}, \mathbf{M p a}$ & Tensile Strength $\mathbf{\Sigma}_{\mathbf{B}, \mathbf{M p a}}$ & Hardness, HV \\
\hline Measured & 680 & 790 & 340 \\
\hline Technical documentation & $>586$ & $>793$ & - \\
\hline
\end{tabular}

Table 2: Results of Chemical Composition of Plunger Rod, Compared With ED Values (In Wt\%).

\begin{tabular}{|c|c|c|c|c|c|c|c|c|c|}
\hline & Steel Grade & C & Si & Mn & $\mathrm{Cr}$ & Mo & $\mathbf{C u}$ & $\mathbf{S}$ & $\mathbf{P}$ \\
\hline Measured & & 0,425 & 0,27 & 0,90 & 0,95 & 0,22 & 0,094 & 0,005 & 0,019 \\
\hline \multirow{3}{*}{$\begin{array}{c}\text { Strength steel } \\
\text { grades } « \mathrm{D} » \text { in } \\
\text { compliance with } \\
\text { API Spec 11B [9] }\end{array}$} & $40 \mathrm{CrMnMoA}$ & $0,37-0,42$ & $0,17-0,40$ & $0,6-0,9$ & $0,9-1,2$ & $0,15-0,25$ & До 0,3 & 0,035 & 0,035 \\
\hline & 30CrMoA & $0,26-0,33$ & $0,17-0,37$ & $0,4-0,7$ & $0,8-1,1$ & $0,15-0,25$ & До 0,3 & 0,025 & 0,025 \\
\hline & 38CrMnTi & $0,37-0,43$ & $0,17-0,37$ & $0,5-0,8$ & $0,4-0,6$ & $0,15-0,25$ & До 0,3 & 0,035 & 0,035 \\
\hline
\end{tabular}




\subsection{Barrel of SPR}

Figure 2 shows the SPR barrel with the valve body.

Barrel studies were carried out for compliance with the technical documentation requirements. Table 3 shows the TD requirements for the barrel material and the mechanical testing results of the sample material.

According to the studies results of the barrel metal mechanical properties, the yield point was $480 \mathrm{MPa}$, and the tensile strength was $820 \mathrm{MPa}$. The sample hardness is 61,5 HRA according to ASTM E140 [7].

To material quality control by hardness parameter, it was interesting to check the presence of a nitrided layer on the barrel surface. Barrel cross section study for microhardness from outer wall was carried out to identify the nitrided layer. To achieve this, metallographic specimen in transverse direction of the barrel section was prepared. The study results are shown in Figure 3.

As a result, the nitrided layer thickness was about $200 \mu \mathrm{m}$ and the base metal hardness was in the range of 240 to 260 HV0, 18.

Table 4 shows studies results of barrel material chemical composition. According to the TD, the barrel material must comply with 38Cr2MoAlA steel grade in compliance with API Spec 11B [9].

According to the studies results of chemical composition, it was found that the SPR barrel material corresponds to $38 \mathrm{Cr} 2 \mathrm{MoAlA}$ steel grade, which complies with the TD requirements.

The SPR barrel material is compliant with the technical documentation requirements regarding mechanical properties and chemical composition.
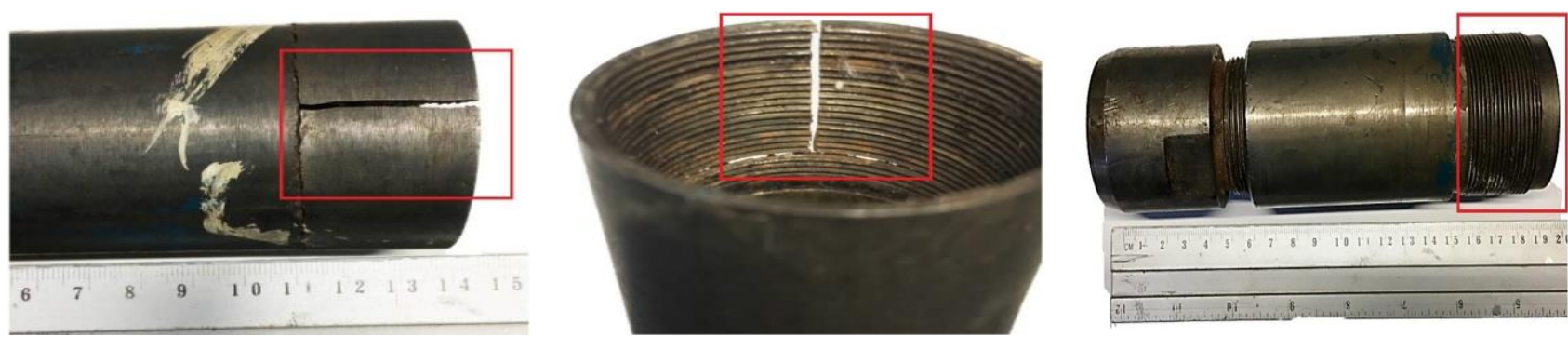

Figure 2: Barrel and Valve Body of SPR: a) Barrel, Outside of Failure Area; b) Barrel, Inner Side of Failure Area; c) Valve Body (Area of Connection With Barrel Is Marked Red).

Table 3: Results of Mechanical Testing of Barrel, Compared With ED Values

\begin{tabular}{|c|c|c|c|c|}
\hline & $\begin{array}{c}\text { Yield Point } \boldsymbol{\sigma 0 . 2}, \\
\text { MPa }\end{array}$ & $\begin{array}{c}\text { Tensile Strength } \boldsymbol{\sigma B}, \\
\text { MPa }\end{array}$ & Presence of Nitrided Layer & Hardness, HRA \\
\hline Measured & 480 & 820 & $\begin{array}{c}\text { Hardness of layer: 1100 HV, at } \\
\text { a depth of 0,127 mm }-800 \mathrm{HV}\end{array}$ & 61,5 \\
\hline $\begin{array}{c}\text { Technical } \\
\text { documentation }\end{array}$ & $>480$ & - & $\begin{array}{c}\text { Hardness of layer: 870 HV, at } \\
\text { a depth of 0,127 mm }-446 \mathrm{HV}\end{array}$ & $55-62$ \\
\hline
\end{tabular}



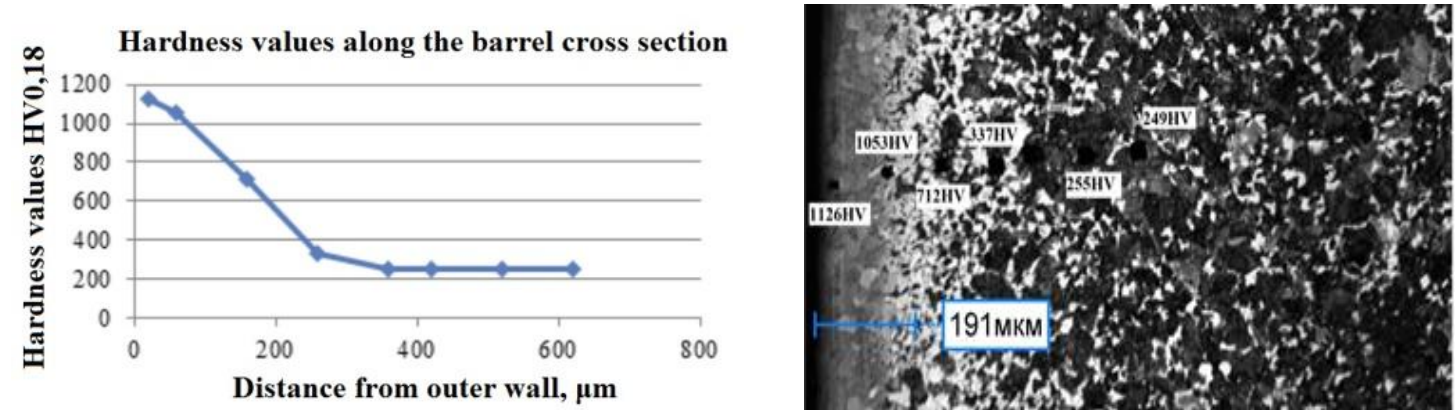

Figure 3: Hardness Values Along the Barrel Cross Section From Outer Wall: a) Relation Graph of Hardness Values and Distance From Outer Wall; b) Surface Microstructure of Barrel Material In Transverse Direction.

Table 4: Results of Chemical Composition of Barrel, Compared With ED Values (In Wt \%).

\begin{tabular}{|l|c|c|c|c|c|c|c|c|c|}
\hline & $\mathbf{C}$ & $\mathbf{S i}$ & $\mathbf{M n}$ & $\mathbf{C r}$ & $\mathbf{M o}$ & $\mathbf{A l}$ & $\mathbf{C u}$ & $\mathbf{S}$ & $\mathbf{P}$ \\
\hline Measured & 0,37 & 0,24 & 0,44 & 1,69 & 0,17 & 0,92 & 0,14 & 0,003 & 0,016 \\
\hline $\begin{array}{l}\text { Chemical composition } \\
\text { of 38Cr2MoAlA in } \\
\begin{array}{l}\text { compliance with API } \\
\text { Spec 11B [9] }\end{array}\end{array}$ & $0,35-0,42$ & $0,20-0,45$ & $0,3-0,6$ & $1,35-1,65$ & $0,15-0,25$ & $0,7-1,1$ & Дo 0,3 & 0,04 & 0,04 \\
\hline
\end{tabular}

\subsection{Failure Analysis}

\subsubsection{Plunger Rod of SPR}

It was established (from figure 1), that the plunger rod destruction occurred on the first thread of threaded rod connection inside the adapter body. Impact marks of mating parts during operation are present on rod guide and rod adapter. During visual inspection of the fracture at increase $\times 30$, it was found that the nature of the destruction is brittle. In Figure 4 , the red line marks the crack initiation point and the beginning of the first thread turn; the yellow line marks the rupture area.

The material structure was studied on a transverse metallographic specimen (Figure 5, a). It was found that the plunger rod material structure is upper bainite [10].

The fracture surface and chemical analysis of corrosion products (Figure 4, marked red) were examined by optical electron microscope. Table 5 shows the chemical composition of corrosion products on the surface (Figure 5, b).

As can be seen from the Table 5, sulphides and chlorides were found on the fracture surface in the crack initiation area. This corresponds to the plunger rod operating conditions in a hydrogen sulfide-containing environment.

Judging by corrosion products and fracture type (brittle), the cause of the plunger rod failure could be sulfide stress corrosion cracking (SSCC). Increased probability of destruction is due to mating parts impact and possible overload during operation. 


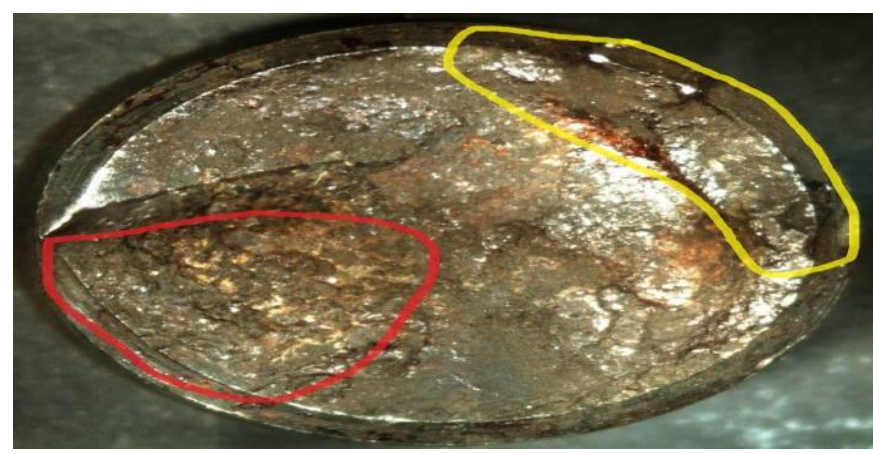

Figure 4: Fracture Surface of Plunger Rod.
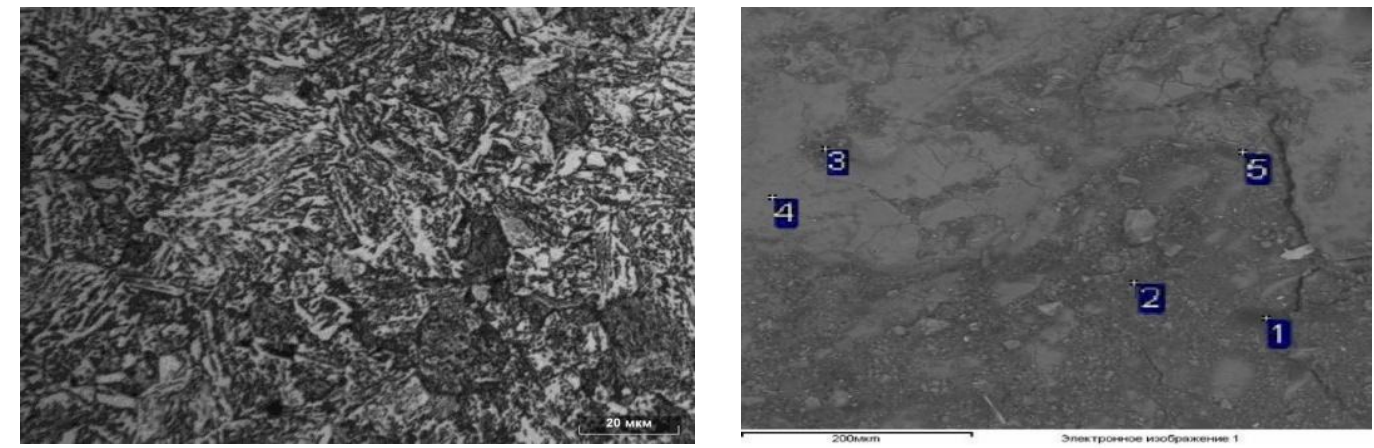

Figure 5: Microstructure of Plunger Rod Material (x500) (a) and Fracture Surface of Plunger Rod (x1000) (b).

Table 5: Chemical Analysis Results of Fracture Surface of Plunger Rod

\begin{tabular}{|c|c|c|c|c|c|c|}
\hline Point & O & Al & Si & S & Cl & Fe \\
\hline 1 & 32,49 & 0,59 & 0,09 & 0,59 & 1,80 & 1,02 \\
\hline 2 & 36,60 & 0,23 & 0,43 & 1,55 & 0,24 & 10,60 \\
\hline 3 & 32,29 & 0,61 & 10,09 & 2,01 & 0,24 & 12,42 \\
\hline 4 & 50,72 & 0,08 & 0,84 & 0,50 & 0,26 & 33,49 \\
\hline 5 & 35,52 & 0,41 & 2,42 & 2,62 & 0,31 & 11,83 \\
\hline
\end{tabular}

\subsection{Barrel of SPR}

As can be seen from Figure 2, the SPR barrel has two cracks in the threaded connection area with the pump suction valve body. During visual inspection of the fracture at increase $\times 30$, it was found that the destruction nature of a longitudinal crack is brittle. In Figure 6, the red line marks the fifth turn of broken barrel thread.

The material structure was studied on a transverse metallographic specimen (Figure 7, a). During metallographic studies, it was found that the barrel material has a ferrite-pearlite structure [10], crystallite size is 8.5.

Figure 7, b shows the eighth turn of thread for studying the fractured barrel thread area. To achieve this, metallographic specimen in longitudinal direction of the barrel thread was prepared. It was found that the cracks depth is $100 \mu \mathrm{m}$.

Figure 8 shows By the nature of crack, shown in Figure 8, it may be assumed that this radial crack is secondary. Initiation and propagation of this crack is result of an increase in tensile loads on the 8th and 9th thread turns area after barrel fracture in the longitudinal direction.

The fracture surface and chemical analysis of corrosion products (Figure 6, marked red) were examined by optical electron microscope. Table 6 shows the chemical composition of the corrosion products on the barrel surface areas (Figure 9). 
Table 6 Shows Sulphides and chlorides were found on the fracture surface in the crack initiation area. It is also known that the operating environment of the SPR barrel was environment with hydrogen sulfide content. Thus, the combination of the high stress concentration in transition zones (mechanical effect) and action of corrosive-active environment, allow for the conclusion that sulfide stress corrosion cracking (SSCC) could be the main cause of the barrel material destruction.
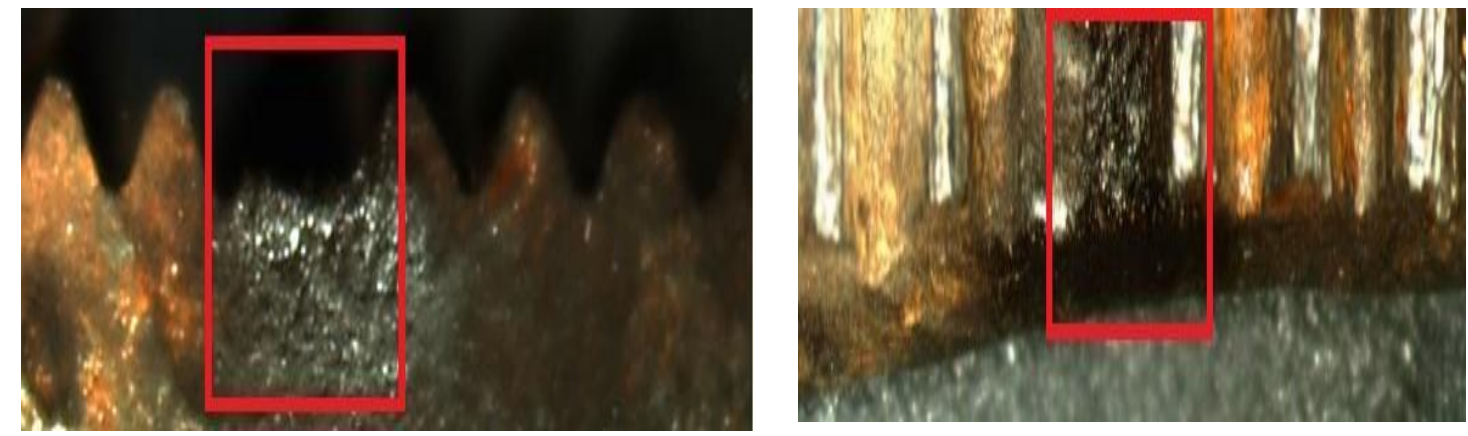

Figure 6: Macrophotographs of Barrel Longitudinal Fracture: a) in Longitudinal Direction; b) View From Inside the Pipe, From the Thread Side.
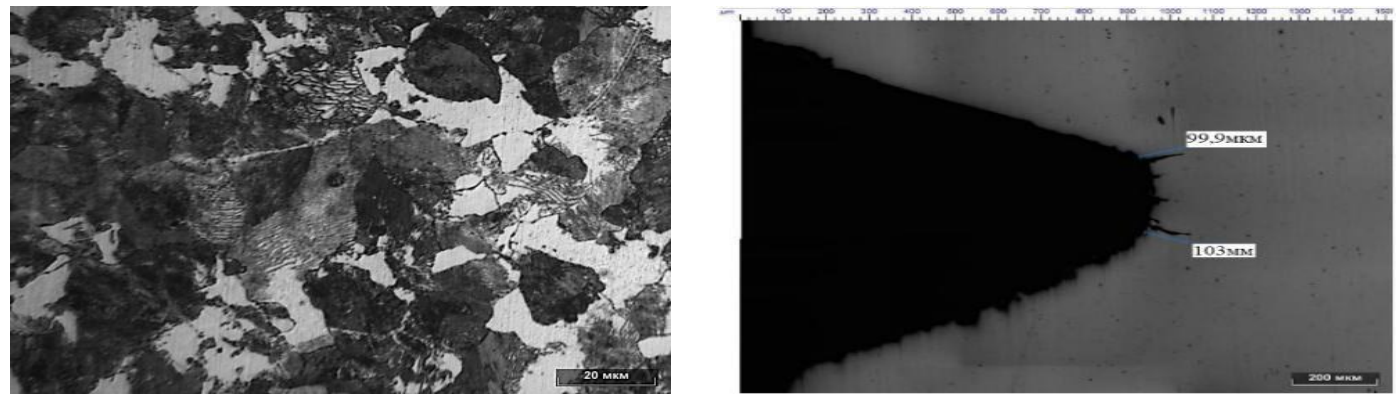

Figure 7: Microstructure of Barrel Material (x500) (a) and Cracks in the Area between 8th and 9th Thread (x100) (b).

Figure 8 shows the fracture propagated along the barrel radius.

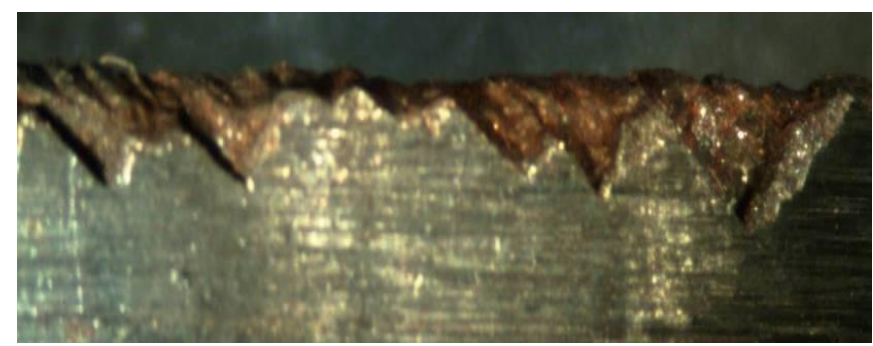

Figure 8: Radial Fracture of Barrel.

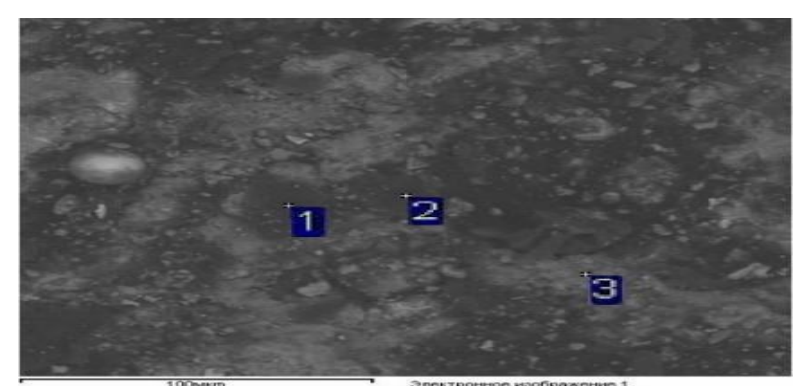

Figure 9: Fracture Surface of Barrel (X1000). 
Table 6: Chemical Analysis Results of Fracture Surface of Barrel

\begin{tabular}{|c|c|c|c|c|c|c|}
\hline Point & O & Na & Si & S & Cl & Fe \\
\hline 1 & 21,14 & 0,18 & - & 1,38 & 0,23 & 4,12 \\
\hline 2 & 5,02 & - & - & 5,73 & 1,96 & 16,59 \\
\hline 3 & 2,85 & - & 0,39 & 0,87 & 0,36 & 74,64 \\
\hline
\end{tabular}

\section{DISCUSSIONS}

Initially, the task was set to exclude the version of details failure due to non-compliance with technical documentation requirements. All tests showed that the materials of the plunger rod and the barrel have parameters according to the technical documentation.

However, materials used in $\mathrm{H}_{2} \mathrm{~S}$-containing environments need to be qualified according to the NACE MR0175 standard, which has requirement for maximum permissible hardness values. Material hardness is an important parameter that can affect the quality of the material [11], and deviation of the hardness from the recommended standard values can lead to a tendency of the material to crack in aggressive environments and, as a result, to destroy equipment [12]. It is important to note that there are no details hardness requirements in the material technical documentation. According to the research results, it was determined that details hardness exceeds maximum permissible values of $33 \mathrm{HRC}$ in accordance with NACE MR0175 [8]. In this case, deviation of the hardness values could affect the material brittleness and be one of the detail failure causes.

B is sulfide stress corrosion cracking (SSCC) [13]. Fracture surfaces studying and corrosion products analysis showed that sulfides and chlorides are present in the fracture area. The combined effect of mechanical loads and corrosionactive environment during operation probably led to destruction by SSCC mechanism. Similar incidents are described in the following papers [14,15].

In summary, 40CrMnMoA and 38Cr2MoAlA steel grades are susceptible to sulphide corrosion destructions in H2Scontaining environments. Because of this, low alloy steels equipment is not recommended for use in hydrogen sulfidecontaining environments [16].

For materials that are operated in aggressive conditions such as $\mathrm{H}_{2} \mathrm{~S}$ and $\mathrm{CO}_{2}$-containing environments, it is necessary to select the appropriate materials, refine the technical documentation in regards to hardness, and also check the materials for compliance with these requirements [17]. Laboratory tests is possible in order to be sure of material resistance in hydrogen sulfide-containing environments.

As protective measures to prevent similar destructions, it is recommended to reduce the sucker rod pumps load, to use of inhibitors to reduce the environment aggressiveness, to control of the materials properties or to use of more corrosionresistant materials for the SPR details [2].

\section{CONCLUSIONS}

Studies have shown that the failure of SPR parts is caused by sulfide stress corrosion cracking. The investigated details comply with the technical documentation, but probably acceptable values for mechanical loads and hydrogen sulfide content were exceeded during operation. Also, incorrect materials selection could be a possible cause of failure SRP parts.

Some standards regulate the hardness requirements of materials used in hydrogen sulfide-containing environment, but there are no such requirements in the technical documentation for the parts investigated. Increased hardness leads to increased tendency to sulphide stress corrosion cracking, so it is recommended to take this parameter into account in the 
documentation. Extension of the SRP details service life and reduction of the probability of destruction is possible with more detailed analysis of the operating conditions and control of the used materials.

\section{REFERENCES}

1. Beketov, S.B., Kuchurin, A.E.: Operation features of wells equipped with sucker rod pumps in fields with slightly cemented reservoir. Gornyi informacionno-analiticheskii byulleten [Mining informational and analytical bulletin], Vol. 12 (2010) 107115 .

2. Ponikarov, S.I., Karimov, L.F., Kalimullin, N.F.: Analysis of failure causes of rod strings during wells operation equipped with suckerrod pumps. Vestnik Kazanskogo tehnologicheskogo universiteta [Bulletin of Kazan Technological University], Vol. 20(3) (2017) 4445.

3. Yamaliev, V.U., Ishemguzhin, I.E., Latypov, B.M.: Friction assessment plunger to barrel of sucker rod pump in design rod string. Izvestiya Samarskogo nauchnogo centra Rossiiskoi akademii nauk [Izvestia of Samara Scientific Center of the Russian Academy of Sciences], Vol. 19(1-1) (2017) 7075.

4. Moradi, S.S.T., Nikolaev, N.I., Chudinova, I.V., Martel, A.S.: Geomechanical study of well stability in high-pressure, hightemperature conditions. Geomechanics and Engineering, Vol. 16(3) (2018) 331339.

5. Laptev, A., Bugay, D.: Fighting against corrosion in oil and gas complex of Russia: Problems and the ways of their solving. European Corrosion Congress, EUROCORR-2010 (2010).

6. Alkhimenko, A.: Corrosion testing of experimental steels for oilfield pipelines. E3S Web of Conferences, Vol. 121. EDP Sciences (2019) 01001.

7. ASTM E140 Standard Hardness Conversion Tables for Metals Relationship Among Brinell Hardness, Vickers Hardness, Rockwell Hardness, Superficial Hardness, Knoop Hardness, Scleroscope Hardness, and Leeb Hardness.

8. NACE MR0175/ISO 15156 Petroleum and natural gas industries - Materials for use in H2S-containing environments in oil and gas production.

9. API SPEC 11B Specification for sucker rods (pony rods, polished rods, couplings and subcouplings) twenty-second edition.

10. Ermakov, B.S., Alhimenko, A.A., Shaposhnikov, N.O., Tsvetkov, A.S., Shirokov, A.V.: Study of the crystallographic texture of pipe steel. Letters on Materials 10.1 (2020) 4853.

11. Dvoinikov, M.V.: Research on technical and technological parameters of inclined drilling. Journal of Mining Institute, Vol. 223 (2017) 8692.

12. Kovalev, M., Lyashenko, D., Kurakin, M., Shakhmatov, A.: Failure analysis of radial bearings used in the refining of petroleum products. E3S Web of Conferences, Vol. 121. EDP Sciences (2019) 03003.

13. Kostitsyna, I., Shakhmatov, A., Davydov, A.: Study of corrosion behavior of carbon and low-alloy steels in CO2-containing environments. E3S Web of Conferences, Vol. 121. EDP Sciences (2019) 04006.

14. Escobar, J. A., Romero, A. F., Lobo-Guerrero, J.: Failure analysis of submersible pump system collapse caused by assembly bolt crack propagation by stress corrosion cracking. Engineering Failure Analysis, Vol. 60 (2016) 1-8.

15. Dvoynikov, M.V., Nutskova, M.V., Blinov, P.A.: Developments Made in the Field of Drilling Fluids by Saint Petersburg Mining University. International Journal of Engineering, Vol. 33(4) (2020) 702711.

16. Davydov, A., Alekseeva, E., Gaev, A.: Specificity to the choice of materials for wellhead equipment. Materials today: Proceedings (2020). 
17. Litvinenko, V.S., Dvoynikov, M.V.: Monitoring and control of the drilling string and bottomhole motor work dynamics. Topical Issues of Rational Use of Natural Resources, Vol. 2 (2019) 804809. 